\title{
AS ARTES E AS TRADIÇÕES POPULARES NORDESTINAS UMA ENTREVISTA COM O PROFESSOR GILMAR DE CARVALHO
}

\author{
Rafael Hofmeister de Aguiar ${ }^{1}$ \\ Francisco Gilmar Cavalcante de Carvalho ${ }^{2}$
}

No texto que segue, apresento o professor Gilmar de Carvalho, que possui vasta obra sobre a cultura popular nordestina, sobretudo sobre a vida e obra de Patativa do Assaré e a literatura de cordel. Optei por realizar a entrevista à distância, retomando temas das conversas que mantive com o intelectual durante a minha pesquisa de campo sobre os cantadores do Cariri cearense em janeiro/fevereiro de 2015, resultando no documentário "De campo e cantadores"3.

Francisco Gilmar Cavalcante de Carvalho ou, simplesmente, Gilmar de Carvalho, como assina a sua obra, é bacharel em Direito (1971) e em Comunicação (1972) pela Universidade Federal do Ceará, mestre em Comunicação Social (1991) pela Universidade Metodista de São Paulo e doutor em Comunicação e Semiótica (1998) pela Pontifícia Universidade Católica de São Paulo. Foi professor do departamento de Comunicação Social da Universidade Federal do Ceará de 1984 a 2010. Mesmo estando aposentado desde 2010, Gilmar de Carvalho não cessou as suas pesquisas e continua produzindo, ao menos, uma obra inédita por ano desde então. Desde de 1994, ao menos, com o livro "Publicidade em cordel", tem se dedicado com afinco à cultura popular. Suas obras incluem: "Madeira Matriz- Cultura e Memória"; "Desenho Gráfico Popular", "Patativa do Assaré- Antologia Poética"; "Poetas do Povo do PiauíImaginário e Indústria Cultural"; "Cem Patativa"; "Mestres da Cultura Tradicional Popular do Ceará"; "Rabecas do Ceará"; "Patativa do Assaré - o sertão dentro de mim"; "Memórias da Xilogravura"; "O Ceará do Ednardo" e "Tirinete-Rabecas da Tradição".

Nesta entrevista, Gilmar de Carvalho aborda a sua obra, as experiências da pesquisa de campo, o amor à cultura popular e a sua relação com o poeta Patativa. Nesse sentido, aproveito o ensejo para agradecer, publicamente, ao professor Gilmar, à sua acolhida e disponibilidade, à sua parceria na minha pesquisa de mestrado e

\footnotetext{
${ }^{1}$ Instituto Federal do Rio Grande do Sul, Campus Rolante, Brasil.

${ }^{2}$ Universidade Federal do Ceará, Brasil.

${ }^{3}$ Disponível em https://www.youtube.com/watch?v=42KBoCNNrow.
} 
doutorado. Ao leitor, convido a contemplar e edificar-se na sabedoria desse grande intelectual brasileiro.

Rafael Hofmeister de Aguiar: Professor Gilmar, o senhor tem se destacado como um pesquisador dedicado às artes e às tradições populares, principalmente, as do sertão nordestino.

Como o senhor começou essa trajetória de sua aproximação acadêmica com as artes e tradições populares?

Gilmar de Carvalho: Nasci na cidade. Meu sertão era de ouvir contar. Eram histórias das pessoas que trabalhavam na casa dos meus pais, das visitas, dos parentes que continuavam no interior.

Todas as vivências da minha infância foram da cidade. O sertão era país estrangeiro e a mudança veio tardiamente.

Em 1976, um amigo fluminense (Jandyr Henriques, de Campos dos Goytacazes) quis conhecer o Cariri cearense e me convidou para ir com ele.

Sentia preguiça destas longas travessias. Viagens que duravam a noite inteira me deixavam apreensivo, mas fui, e fiz bem em ter ido.

Juazeiro do Norte era um enigma para mim. Precisava decifrá-lo.

Encontrei algo que me marcou profundamente e provocou uma reviravolta na minha visão de mundo e no meu conceito de cultura.

Impossível não mexer na emoção da descoberta das romarias, na visita aos lugares sagrados dos peregrinos, aos ateliês dos artistas, ao mercado, à Matriz do Juazeiro (onde se deu o "milagre " da hóstia que se transformou em sangue, quando da comunhão da beata. à Capela do Socorro onde o "Padim" está enterrado. Era tanta coisa e eu ficava cada vez mais aturdido, perplexo.

Iria precisar de muito tempo para processar tantas informações, que me chegavam a uma velocidade estonteante.

Relembro a subida da ladeira do Horto, as casinhas enfileiradas, e o Padre Cícero no topo da colina, como se fosse um farol.

Na subida, santos de gesso secavam ao vento e ao sol, artesãos faziam chapéus de palha para os romeiros, benditos se esgueiravam pelas portas e nos sinalizavam que o território era sagrado. 
Olhando para dentro das casas, veríamos as paredes votivas, com santos emoldurados, fitas, flores de tecidos, velas. Era Juazeiro do Norte em sua plenitude. A cidade foi fundada a partir de um líder que atraía romeiros, de muitos lugares, em busca de uma vida melhor.

Voltei com o propósito de digerir aquilo tudo, de redirecionar minhas pesquisas, minha escrita, e minha inserção neste mundo tão rico quanto diverso do meu.

Rafael Hofmeister de Aguiar: Quais obras suas o senhor destaca no campo da pesquisa das manifestações populares?

Gilmar de Carvalho: "Artes da Tradição- Mestres do Povo", de 2005, em parceria com Francisco Sousa, fotógrafo e filósofo, com quem trabalho desde 2002, foi resultado de viagens pelo interior do Ceará que nos renderam cinquenta textos publicados, inicialmente, pelo jornal Diário do Nordeste, em 2003.

"Mestres da Cultura Tradicional Popular do Ceará", de 2006, também em parceria com Francisco Sousa, uma encomenda da Secretaria da Cultura do Estado para registrar histórias de vida, saberes e fazeres destes homens e mulheres, que interferem, com um padrão de excelência, na vida cultural. É o campo do feito a mão, dos folguedos, fazendo da expressão tradicional popular do Ceará, uma das vigorosas e criativas do Brasil.

"Moisés Matias de Moura", de 2011, depois de uma apresentação crítica, traz uma coletânea de folhetos deste pernambucano de Garanhuns (1891), radicado em Fortaleza, onde faleceu em 1976, encontrados na Casa de Rui Barbosa e em outros acervos importantes, bem como de visitas à família do poeta. Foi uma forma de falar também sobre Fortaleza dos anos 1940 e 1950, quando ele estava no seu apogeu e escreveu a maior parte dos 120 títulos que publicou.

"Mestre Noza, o santeiro do Padre Cícero", de 2012, livro que organizei, com fotos de Francisco Sousa, trouxe um conjunto de 59 esculturas do mestre pernambucano de Taquaretinga do Norte (1897 / 1983), radicado em Juazeiro do Norte, doados ao Museu de Arte da UFC pelo professor Renato Casimiro. 
"A Xilogravura de Juazeiro do Norte", de 2014, foi publicado pelo IPHAN. Acompanhei esta manifestação em Juazeiro do Norte, desde a fundação da primeira gráfica, em 1909, que editava o semanário "O Rebate", veículo para a emancipação política do povoado, obtida em 1911, até cem anos depois.

"Tirinete- Rabecas da Tradição", de 2018, também parceria com Francisco Sousa, pesquisa premiada pelo IPHAN (Prêmio Rodrigo Melo Franco de Andrade, 2014), no qual levantamos histórias de vidas de 175 rabequeiros e 10 luthiers cearenses e mostramos a importâncias deste instrumento para o reisado, os dramas, o teatro de bonecos. a dança de São Gonçalo e as festas nos terreiros das fazendas .

Rafael Hofmeister de Aguiar: Quais são os seus projetos atuais?

Gilmar de Carvalho: Um livro sobre o cordel no Ceará. Já tenho 150 páginas escritas. O ponto de partida foi implodir a ideia de que cordel era apenas o folheto de feira. Trabalho com cantoria, embolada, benditos e aboios. Ocupo-me das tipografias, dos editores, e tanto com grandes nomes (Caboclo, Expedito, Cristo Rei), como com poetas que fizeram um cordel, que não tinham tanta competência, mas se expressaram.

Também preparo um livro sobre a memória dos velhos vaqueiros de Morada Nova (150 $\mathrm{km}$ de Fortaleza). Hoje, não temos mais as viagens, como a que foi acompanhada pro Guimarães Rosa, para levar boiadas de uma fazenda para outra. Tudo se resolve com o caminhão. Também não temos vaqueiros encourados procurando a rês desgarrada no meio dos cipós. O gado está confinado e o vaqueiro trabalha, muitas vezes, de jeans, pilotando uma moto.

Rafael Hofmeister de Aguiar: O professor tem uma vasta obra sobre o folheto de cordel do Nordeste brasileiro, tendo feito recolha de inúmeros poetas. Nesse sentido, qual relação o senhor considera que o folheto brasileiro guarda com o cordel ibérico de raiz medieval?

Gilmar de Carvalho: O nosso cordel é uma maravilhosa adaptação para o contexto brasileiro de um modelo europeu, trazido na bagagem do português. 
Temos nossas marcas e influências indígena, africana, cigana. Nosso "moinho" processou tudo com muita competência, malícia, sensibilidade e emoção.

Essa ideia de adaptação tomo de empréstimo a Antonio Candido, não falando exatamente de cordel, mas da formação da literatura brasileira.

Não foi à toa que o os "Cinco livros do Povo", dos quais tratou Câmara Cascudo, faziam parte do catálogo da Impressão Régia, em 1815. Estes títulos eram velhos conhecidos nossos.

A divulgação do cordel era feita oralmente. Cordel e cantoria se imbricavam muito mais neste período. A interiorização das tipografias, proibidas até 1808, trouxe muitos jornais de pequenos formatos e tiragens inexpressivas, mas com muita importância para a nossa história cultural.

A figura do poeta editor se consolidou e estes pequenos, mas aguerridos empreendedores, definiram um formato e procedimentos de edição que passaram a valer até hoje, apesar de toda a evolução das técnicas de reprodução.

As controvérsias são saudáveis no campo das ideias, mas, para mim, o cordel brasileiro tem matriz lusa.

Rafael Hofmeister de Aguiar: Ainda no mesmo ângulo da questão anterior, o senhor considera que há alguma relação entre os cantadores nordestinos e os trovadores medievais?

Gilmar de Carvalho: Sim, mas tudo muito difuso. Digamos que estamos inseridos em um contexto e participamos de um processo. Podemos encontrar fragmentos, sugestões, indícios destas influências.

Nossa oralidade sempre foi forte e continua, deslocada para as tecnologias de ponta, daí o sucesso das mensagens de voz do "what's app" ou das telenovelas. Nosso analfabetismo, apesar de mascarado por estatísticas que elogiam nosso sistema educacional, ainda é forte.

O livro é um produto de luxo, inacessível e/ou desinteressante para muitos.

Nosso canto ancestral se sustenta na memória. Alguns visitantes, que vinham em expedições, registraram cantos em partituras (Spix e Martius), por exemplo. Mário de Andrade foi fundamental também neste sentido e deu seriedade à pesquisa folclórica. 
Nosso canto é poético, mas pode ter sido canto de guerra; é improvisado, mas se codificou, muitas vezes. Tem regras e modalidades, como a cantoria, mas pode ser áspero e gutural, onomatopaico, como o aboio. É rico e diverso demais para caber nos escaninhos propostos por muitos estudiosos.

Rafael Hofmeister de Aguiar: A sua trajetória é marcada pelo encontro entre a Comunicação, sua área de formação, e as poéticas advindas das tradições populares. Nesse percurso, muitas vezes, o professor realizou pesquisas em campo. Como se deu essas imersões em pesquisas em campo? Qual a importância delas para o seu trabalho? A pesquisa de campo é um instrumento muito comum da Antropologia. A Antropologia contribuiu em algum momento da sua trajetória como pesquisador?

Gilmar de Carvalho: Venho da Comunicação, me graduei, em 1972, e podia ser jornalista e também

publicitário. Trabalhei pouco nos jornais, mas passei oito anos das agências de publicidade. Entrei para o magistério superior por concurso, em 1984. No Mestrado, feito na Universidade Metodista de São Paulo (campus em São Bernardo do Campo) aprofundei as leituras que foram apenas sugeridas na graduação. No doutorado, na Comunicação e Semiótica, na PUC de São Paulo, fui orientado pela professora Jerusa Pires Ferreira, que tinha formação em Letras, uma cultura humanística muito sofisticada, e nenhum preconceito em relação ao que chamava de "cultura das bordas". Estudei no ensino fundamental e médio com os Jesuítas, e , esse tempo, o latim fazia parte da grade curricular.

Meu "mix" veio do ancestral com o "pop", das tradições com o consumo. Estudei o folheto de cordel publicitário no Mestrado, publicado com o título de "Publicidade em Cordel", pela editora Maltese (no momento, negocio uma terceira edição). O doutorado me deu abertura para a Semiótica da Cultura, com os teóricos da antiga União Soviética, levados para a sala de aulas pela professora Jerusa Pires Ferreira e pelo professor Norval Baitello Jr. Estudei o Padre Cícero na xilogravura e no cordel. 
A tese foi publicada com o título de "Madeira Matriz", pela Annablume, esgotada, está sendo reeditada, com prefácio do Professor Ralph Della Cava. Ganhou o Prêmio Sílvio Romero, de melhor monografia sobre culturas populares no Brasil, em 1998.

Tenho a curiosidade do repórter e a escuta de quem é psicanalizado. Nunca quis ser antropólogo, ainda que um dos meus maiores amigos, o professor Ismael Pordeus Jr. estude as religiões afro-brasileiras. O campo é essencial para mim. Fujo do sedentarismo, da pesquisa burocrática, e conheço gente interessante, curiosa, ímpar. As viagens pelo Ceará e parte do Nordeste, são também viagens interiores. Eu me conheço mais, aprendo a respeitar o outro, e a conviver com a diferença, o que não tem sido muito estimulado no Brasil ultimamente.

Rafael Hofmeister de Aguiar: O seu nome está ligado à figura de Patativa do Assaré. Qual foi a sua relação com o poeta? Como essa relação foi importante para a sua trajetória como pesquisador?

Gilmar de Carvalho: Tive muita curiosidade pelo poeta Patativa do Assaré e me aproximei dele. Tornamo-nos amigos. Fazia visitas frequentes ao poeta, em sua casa no Assaré. Subimos, mais de uma vez, a Serra de Santana, onde ele nasceu e fazia jogos poéticos com seu primo Geraldo Gonçalves de Alencar, falecido ano passado. Tenho dez livros com ele, sobre ele, organizados ou escritos por mim.

Foi uma das pessoas mais interessantes que conheci. Era genial. Não tenho outra palavra para defini-lo.

Era poesia em permanente fluxo. Tinha uma memória privilegiada e uma consciência política muito bem construída. Apesar de cego, foi leitor voraz, dos poetas românticos brasileiros, dos quais tinha uma admiração grande pelo Castro Alves, a Camões.

Patativa foi um marco na minha trajetória de pesquisador. Com sua morte, em 2012, decidi conhecer o Ceará por inteiro, pois estava muito ligado, até então, ao Cariri. Este salto foi decisivo para os novos livros como "Artes da Tradição", o "Mestres da Cultura Tradicional Popular do Ceará"e, mais recentemente, o "Tirinete - Rabecas da Tradição". O Ceará passou a ser minha bússola, meu foco, e Patativa foi a voz que ecoou gracejos, poesias de amor, elogiou a natureza, os contatos pessoais, o cordel e a política, com a 
defesa da Reforma Agrária, pela qual ele lutou bravamente, pedindo a terra para quem nela trabalhasse.

Rafael Hofmeister de Aguiar: Qual importância o senhor atribui a Patativa do Assaré na atualidade?

Gilmar de Carvalho: Defendo a tese de que Patativa fez um grande cordel. Sua poesia tinha as marcas da voz e foram feitas para serem lidas em voz alta. Seu legado foi grande.

Ele tem cada vez mais importância no contexto nacional.

Foi uma voz que enunciou verdades e tomou o partido do economicamente mais fraco. Tratou dos grandes temas da Humanidade e fez uma poesia de qualidade, nada panfletária, que vai permanecer.

O Ceará está preocupado com esta permanência e eu fui convidado pela Secult, a organizar um livro que será lido e distribuído nas escolas públicas, com o melhor da sua poesia. Pensamos que esta será uma ofensiva para que ele chegue aos "millenials", aos que nasceram depois de sua morte, quando tinha presença na mídia, era homenageado e seus livros circulavam mais.

Recebido 01/07/2019

Aprovado 24/07/2019 